\title{
RANCANG BANGUN RECTIFIER PADA RECTENNA UNTUK TRANSFER DAYA WIRELESS PADA FREKUENSI 2,45 GHZ
}

\author{
Endah Hijriani ${ }^{1}$, Baso Maruddani ${ }^{2}$ dan Efri Sandi ${ }^{3}$ \\ ${ }^{1,2,3}$ Prodi Pendidikan Vokasional Teknik Elektronika Fakultas Teknik Universitas Negeri Jakarta \\ Email: $\underline{\text { endahhijriani@gmail.com, }{ }^{2} \text { basomaruddani@unj.ac.id, }{ }^{3} \text { efri.sandi@ unj.ac.id }}$
}

\begin{abstract}
Abstrak-Sistem Transfer Daya Wireless merupakan sistem yang digunakan untuk memanfaatkan energi elektromagnetik yang tersebar bebas di udara dengan mengolah sumber energi untuk mengisi daya pada perangkat elektronik berdaya rendah. Salah satu sumber energi yang mudah diperoleh karena ketersediaannya yang cukup melimpah adalah access point (Wi-Fi). Rectenna adalah perangkat yang dapat digunakan untuk mengubah gelombang elektromagnetik di udara menjadi arus listrik searah. Rectenna terdiri dari antena dan rangkaian penyearah (rectifier). Antena digunakan untuk menangkap gelombang elektromagnetik yang dipancarkan oleh sumber RF. Daya yang dierima oleh antena akan diteruskan ke rangkaian rectifer, untuk diubah menjadi arus listrik searah (DC). Penelitian bertujuan untuk merancang, membuat, dan mengukur parameter rangkaian rectifier pada rectenna yang mampu bekerja pada jangkauan frekuensi $2,45 \mathrm{GHz}$. Setelah dirancang dari hasil simulasi menggunakan software ADS 2011didapatkan frekuensi kerja 2,449 GHz, output voultage 2,027 Volt, Return S11(Return Loss) 34,87, dan VSWR 1,037. Pada hasil pengukuran pada signal generator pada frekuensi $2,45 \mathrm{GHz}$ didapatkan output voltage dengan input $-5 \mathrm{dBm}$ sebesar 54,8 mV, S11 (Return Loss) sebesar -10,416 dB, dan VSWR sebesar 1,862. Hasil pengukuran kedua dengan menggunakan access point Wi-Fi pada jarak 5 $\mathrm{cm}$ didapatkan output voltage sebesar 2,066 Volt, sedangkan pada jarak $20 \mathrm{~cm}$ didapat output voltage sebesar 0,092 mV.
\end{abstract}

Kata Kunci : Rectifier, Rectenna, Transfer Daya Wireless, stage, Single Stub, Output Voltage, Advance Design System (ADS) 2011,, Signal Generator, Vector Network Analyzer (VNA), dan access point WiFi.

\begin{abstract}
The Wireless Power Transfer System is a system used to harness the free electromagnetic energy in the air by processing energy sources to charge on low-power electronic devices. One source of energy that is easily obtained because of its availability is quite abundant access point (Wi-Fi). Rectenna is a device that can be used to convert electromagnetic waves in the air into direct electric currents. Rectenna consists of an antenna and a rectifier circuit. Antenna is used to capture the electromagnetic waves emitted by RF sources. The power received by the antenna will be forwarded to the rectifier circuit, to be converted to direct current (DC). The study aimed to design, construct, and measure the parameters of rectifier circuits in rectenna capable of working at a frequency range of $2.45 \mathrm{GHz}$. After designed from the simulation results using ADS software 2011didapatkan working frequency of 2.449 GHz, output voultage 2.027 Volt, Return S11 (Return Loss) -34.87, and VSWR 1.037. On the result of measurement at signal generator at frequency $2,45 \mathrm{GHz}$ obtained output voltage with input $-5 \mathrm{dBm}$ equal to 54,8 mV, S11 (Return Loss) equal to -10,416 dB, and VSWR equal to 1,862. The second measurement result using Wi-Fi access point at $5 \mathrm{~cm}$ distance obtained output voltage of 2.066 Volt, while at a distance of $20 \mathrm{~cm}$ obtained output voltage of $0.092 \mathrm{mV}$.
\end{abstract}

Keywords : Rectifier, Rectenna, Transfer Daya Wireless, stage, Single Stub, Output Voltage, Advance Design System (ADS) 2011, Signal Generator, dan Vector Network Analyzer (VNA), access point Wi-Fi.

\section{PENDAHULUAN}

Semakin berkembangnya teknologi dibutuhkan upaya dalam penyediaan atau penghematan energi, Pemanenan energi dari gelombang elektromagnetik menjadi menarik untuk dikembangkan sebagai sumber untuk mengisi daya pada perangkat elektronik berdaya rendah yang disebut dengan sistem Transfer Daya Wireless.
Sistem Transfer Daya Wireless adalah sistem yang digunakan untuk memanfaatkan energi elektromagnetik yang tersebar bebas di udara. Kemudian energi tersebut dilakukan pengolahan sehingga menghasilkan daya yang dapat digunakan untuk mencatu perangkat elektronik berdaya rendah.

Salah satu alat utama pada Sistem Transfer Daya Wireless adalah rectenna. Rectenna adalah 
perangkat yang dapat digunakan untuk mengubah gelombang elektromagnetik di udara menjadi arus listrik searah. Rectenna umumnya terdiri dari antena dan rangkaian penyearah (rectifier). Antena digunakan untuk menangkap gelombang elektromagnetik yang dipancarkan oleh sumber RF. Daya yang diterima oleh antena pada rectenna akan diteruskan ke rangkaian rectifier, untuk diubah menjadi arus listrik searah (DC).

Daya yang ditangkap antena berupa sinyal gelombang elektromagnetik akan disearahkan menjadi tegangan DC oleh rangkaian rectifier dengan mematchingkan terlebih dahulu sesuai dengan nilai matching impedance yang ada di antena, kemudian tegangan DC yang didapat akan dinaikan lagi hingga mencapai nilai tegangan yang konstan menggunakan rangkaian rectifier yang telah dimodifikasi sebagai pelipat tegangan. Energi listrik DC keluaran yang telah dikuatkan tersebut diharapkan dapat dimanfaatkan untuk memenuhi kebutuhan energi listrik berdaya rendah.

\section{METODOLOGI PENELITIAN}

Metode penelitian yang digunakan adalah Metode Research and Development (R\&D).

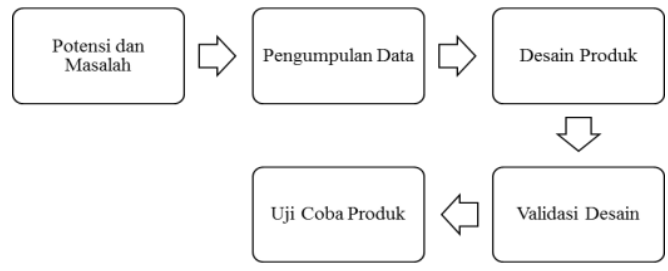

Gambar 1. Langkah Metode Research and Development (R\&D) yang digunakan dalam Penelitian

Peneliti mengambil beberapa langkah penelitian pengembangan, yaitu:

A. Potensi dan Masalah

Penelitian bermula dari potensi gelombang elektromagnetik yang terdapat dalam gelombang frekuensi radio (Radio Frequency/ RF) bebas di udara untuk digunakan sebagai sumber energi alternatif.

\section{B. Pengumpulan Data}

Pengumpulan data berbagai informasi yang digunakan sebagai bahan untuk perencanaan desain rectifier sesuai yang diharapkan.

C. Desain produk

Rectifier pada rectenna yang dihasilkan dalam penelitian, didesain dengan bantuan software simulasi yakni menggunakan Advance Design System 2011 dalam perancangan sesuai dengan pengumpulan data.

\section{Validasi Desain}

Validasi desain merupakan hasil simulasi dari desain produk pada software simulasi, dimana untuk menilai apakah rancangan rectifier sesuai dengan yang diharapkan.

E. Uji Coba Produk

Uji Coba produk meliputi fabrikasi rectifier, penyolderan komponen rectifier, dan pengukuran hasil fabrikasi dan penyolderan rectifier.

\section{HASIL DAN PEMBAHASAN \\ A. Hasil Akhir Rangkaian Rectifier Pada Rectenna}

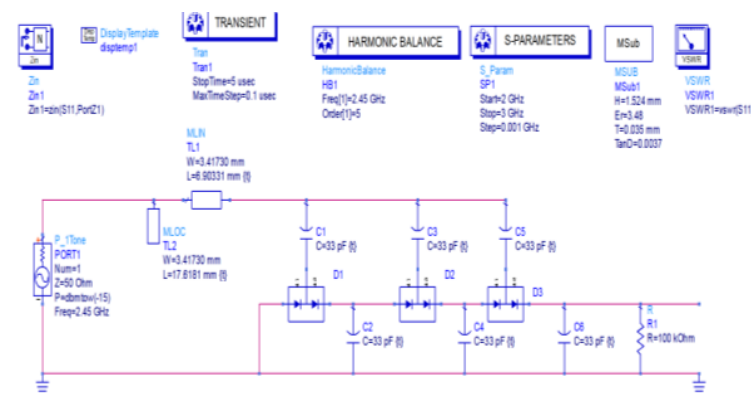

Gambar 2. Penggabungan Single Stub Match ke dalam Rangkaian Rectifier 3 Stages

Tabel 1 adalah daftar nilai komponen rangkaian Rectifier pada retenna.

TABEL 1

DAFTAR NILAI KOMPONEN RANGKAIAN RECTIFIER

\begin{tabular}{ccc}
\hline Komponen & $\begin{array}{c}\text { Nilai } \\
\text { (Spesifikasi) }\end{array}$ & Jumlah \\
\hline Dioda schottky & HSMS 2862 & 3 \\
\hline Kapasitor & 33 Pf & 6 \\
\hline Antena Wi-Fi & TL-WN722N & 1 \\
\hline Wi-Fi Router & $\begin{array}{c}\text { En-Genius } \\
\text { ENS202E }\end{array}$ & 1 \\
\hline
\end{tabular}

TABEL 2

DAFTAR NILAI DARI LEBAR, JARAK STUB KE BEBAN (DS) DAN PANJANG STUB (LS)

\begin{tabular}{|c|c|}
\hline Parameter & Nilai $(\mathbf{m m})$ \\
\hline ds & 8,66 \\
\hline Is & 17,38 \\
\hline
\end{tabular}

\section{B. Hasil Desain Layout dan Fabrikasi Rectifier pada Rectenna}

Setelah semua rangkaian Rectifier pada Rectenna dirancang pada software ADS 2011 dan semua nilai komponen yang telah disesuaikan dengan yang terdapat di pasaran serta ukuran saluran mikrostrip yang telah ditentukan, langkah selanjutnya adalah membuat 
layout Rectifier pada Rectenna menggunakan software Altium Designer Summer yang nantinya akan lanjut proses fabrikasi.

Gambar 2 adalah gambar hasil desain layout Rectifier pada Rectenna pada Altium 2013.

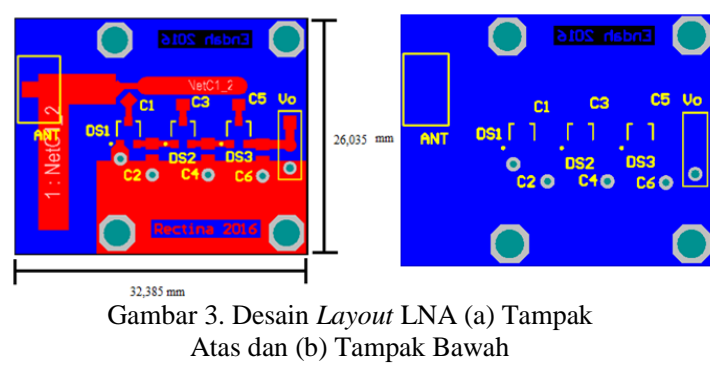

Setelah dilakukan simulasi untuk mendapatkan hasil parameter yang sesuai dengan spesifikasi yang diharapkan, maka fabrikasi rectifier pada rectenna dengan konfigurasi 3 stages dapat direalisasikan. Gambar 3 adalah fabrikasi rectifier dan penyolderan yang telah direalisasikan sesuai dengan perancangan.

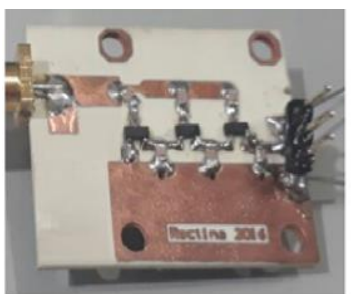

(a)

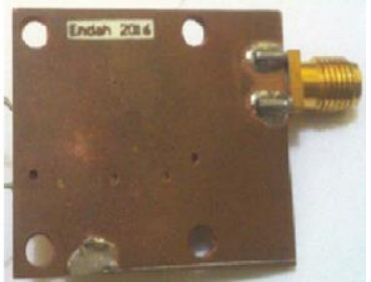

(b)
Gambar 4. Hasil Fabrikasi LNA (a) Tampak Depan dan (b) Tampak Belakang

C. Hasil Pengukuran Rectifier

1) Pengukuran Tegangan

Hasil pengukuran tegangan rectifier dengan signal generator ditunjukkan pada Tabel 3.

Sedangkan untuk hasil pengukuran dengan menggunakan perangkat tambahan antenna ditunjukkan pada Tabel 4.

2) Pengukuran VSWR

Pada hasil pengukuran VSWR di frekuensi 2,45 didapatkan sebesar 1,862. Sedangkan hasil pengukuran VSWR terbaik terjadi pada frekuensi $2,550 \mathrm{GHz}$ dengan nilai VSWR 1,833.

3) Pengukuran $S_{11}$ (Return Loss)

Pada hasil pengukuran $S_{11}$ (Return Loss) di frekuensi 2,45 didapatkan sebesar $-10,416$ dB. Sedangkan hasil pengukuran $S_{11}$ (Return Loss) terbaik terjadi pada frekuensi 2,550 GHz dengan nilai VSWR -10,586 dB.
TABEL 3

HASIL PENGUKURAN RECTIFIER DENGAN SIGNAL GENERATOR

\begin{tabular}{cccc}
\hline Input RF (dBm) & $\begin{array}{c}\text { Tengangan } \\
\text { Output (V) }\end{array}$ & Arus (A) & Daya (watt) \\
\hline 10 & $1.59 \mathrm{~V}$ & $0.4 \mu \mathrm{A}$ & $0.636 \mu$ watt \\
\hline 9 & $1.355 \mathrm{~V}$ & $0.2 \mu \mathrm{A}$ & $0.271 \mu w$ watt \\
\hline 8 & $1.351 \mathrm{~V}$ & $0.1 \mu \mathrm{A}$ & $0.1351 \mu w a t t$ \\
\hline 7 & $0.945 \mathrm{~V}$ & & \\
\hline 6 & $0.76 \mathrm{~V}$ \\
\hline 5 & $0.6 \mathrm{~V}$ \\
\hline 4 & $0.48 \mathrm{~V}$ \\
\hline 3 & $377.2 \mathrm{mV}$ \\
\hline 2 & $299.6 \mathrm{mV}$ \\
\hline 1 & $239.3 \mathrm{mV}$ \\
\hline 0 & $193.5 \mathrm{mV}$ \\
\hline-1 & $152.5 \mathrm{mV}$ \\
\hline-5 & $54.8 \mathrm{mV}$ \\
\hline-10 & $16.5 \mathrm{mV}$ \\
\hline-15 & $5.7 \mathrm{mV}$ \\
\hline-20 & $2.3 \mathrm{mV}$ \\
\hline-25 & $1.2 \mathrm{mV}$ \\
\hline-26 & $1.2 \mathrm{mV}$ \\
\hline-28 & $1.1 \mathrm{mV}$ \\
\hline-30 & $0.9 \mathrm{mV}$ \\
\hline-32 & $0.9 \mathrm{mV}$ \\
\hline-35 & $0.7 \mathrm{mV}$ \\
\hline
\end{tabular}

TABEL 4

HASIL PENGUKURAN MENGGUNAKAN PERANGKAT TAMBAHAN ANTENA

\begin{tabular}{|c|c|c|}
\hline Jarak (cm) & $\begin{array}{l}\text { Tegangan output } \\
\text { (V) }\end{array}$ & Arus (A) \\
\hline $5 \mathrm{~cm}$ & $2.066 \mathrm{~V}$ & $20 \mu \mathrm{A}$ \\
\hline $7 \mathrm{~cm}$ & $879 \mathrm{mV}$ & $18 \mu \mathrm{A}$ \\
\hline $10 \mathrm{~cm}$ & $770 \mathrm{mV}$ & $7 \mu \mathrm{A}$ \\
\hline $12 \mathrm{~cm}$ & $170 \mathrm{mV}$ & \multirow{4}{*}{$\begin{array}{l}\text { Arus }=0,1 \mu \mathrm{A} \\
\text { sehingga tidak } \\
\text { terbaca alat uku }\end{array}$} \\
\hline $15 \mathrm{~cm}$ & $113,3 \mathrm{mV}$ & \\
\hline $17 \mathrm{~cm}$ & $52 \mathrm{mV}$ & \\
\hline $20 \mathrm{~cm}$ & $0.092 \mathrm{mV}$ & \\
\hline
\end{tabular}

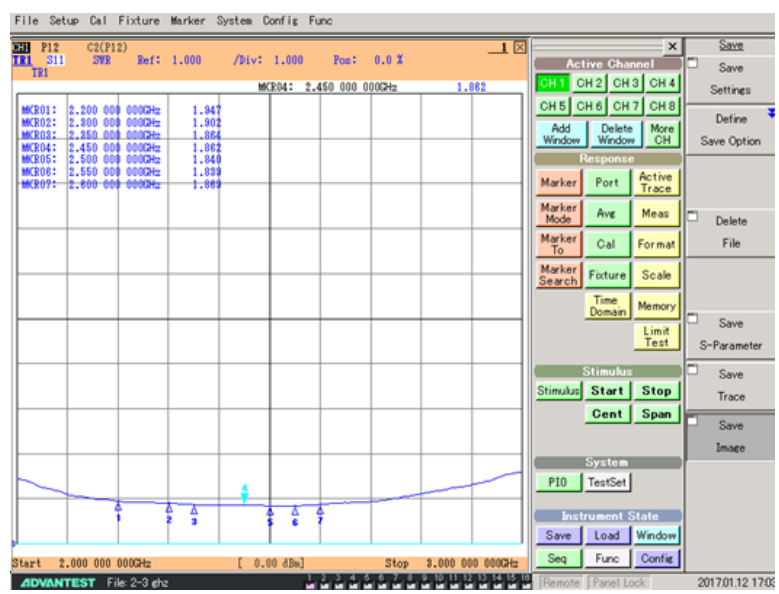

Gambar 5. Hasil Pengukuran VSWR 


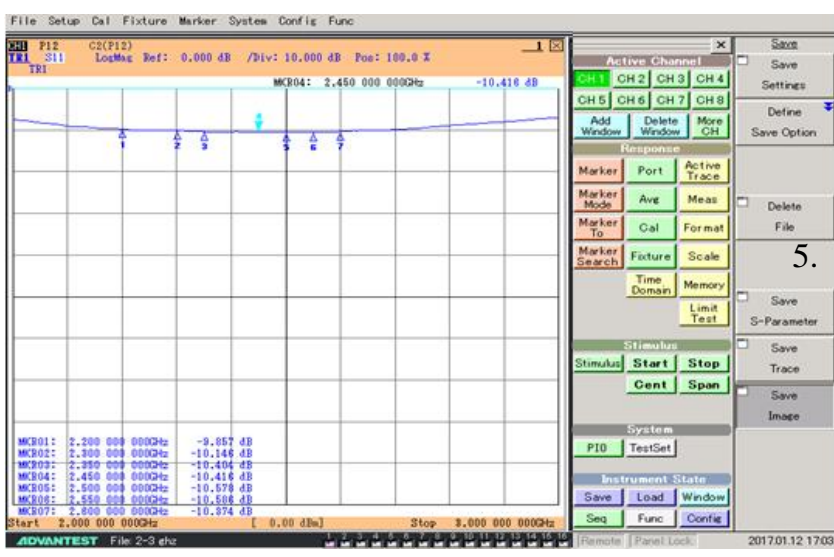

Gambar 6. Hasil Pengukuran $\mathrm{S}_{11}$ (Return Loss)

\section{Perbandingan Hasil Simulasi dan Pengukuran}

TABEL 5

HASIL PERBANDINGAN ANTARA SPESIFIKASI AWAL DENGAN PENGUKURAN HASIL SIMULASI, DAN HASIL PENGUKURAN RANGKAIAN RECTIFIER

\begin{tabular}{cccc}
\hline Parameter & $\begin{array}{c}\text { Spesifikasi } \\
\text { Awal }\end{array}$ & $\begin{array}{c}\text { Hasil Simulasi } \\
\text { pada } \mathbf{- 5} \mathrm{dBm}\end{array}$ & $\begin{array}{c}\text { Hasil } \\
\text { pengukuran }\end{array}$ \\
\hline Frekuensi kerja & $2,45 \mathrm{GHz}$ & $2,449 \mathrm{GHz}$ & $2,45 \mathrm{GHz}$ \\
\hline Tegangan output & $2 \mathrm{Volt}$ & $2,027 \mathrm{Volt}$ & $54,8 \mathrm{mV}$ \\
\hline $\mathrm{S}_{11}$ (Return Loss) & $-10 \mathrm{~dB}$ & $-34,87 \mathrm{~dB}$ & $-10,416 \mathrm{~dB}$ \\
\hline VSWR & $<2$ & 1,037 & $1,862 \mathrm{~dB}$ \\
\hline
\end{tabular}

\section{KESIMPULAN}

Berdasarkan hasil penelitan yang telah didesain sebuah Rectifier pada Rectenna yang mampu bekerja pada jangkauan frekuensi 2,45 $\mathrm{GHz}$ dengan perangkat lunak Advance Design System (ADS) 2011, dapat disimpulkan bahwa:

1. Hasil perancangan Rectifier pada frekuensi 2,45 $\mathrm{GHz}$ dengan jangkauan 2,4-2,5 GHz berdasarkan simulasi telah memenuhi spesifikasi yang diharapkan yaitu dengan nilai Output Voltage sebesar 2,027 Volt, $\mathrm{S}_{11}$ (Return Loss) sebesar -31,529 dB, dan VSWR 1,089. Impedansi input 50,022 j4,278.

2. hasil pengukuran menggunakan Vector Network Analyzer menunjukan perbedaan dengan hasil simulasi. Pada pengukuran di frekuensi 2,45 GHz didapatkan $\mathrm{S}_{11}$ (Return Loss) sebesar -10,416 dB, dan VSWR sebesar 1,862 .

3. Hasil pengukuran output voltage menggunakan Signal Generator dengan input $\mathrm{RF}$ sebesar $-5 \mathrm{dBm}$, didapatkan hasil tegangan sebesar $54,8 \mathrm{mV}$. Terjadi penurunan tegangan sebebsar 1,9722 Volt dari hasil simulasi.

4. Hasil pengukuran output voltage yang didapat dari access point dengan jarak terdekat yaitu $5 \mathrm{~cm}$, didapatkan hasil tegangan sebesar 2,066 Volt dengan arus 20 $\mu A$.sedangkan jarak terjauh $20 \mathrm{~cm}$ didapat tegangan sebesar $0,092 \mathrm{mV}$ dengan arus $\leq$ $0,1 \mu \mathrm{A}$.

Dalam pengukuran menggunakan Signal Generator, Vector Network Analyzer dan multimeter digital terdapat perbedaan antara hasil simulasi dan pengukuran. Hal ini disebabkan, nilai komponen pasif yang memiliki nilai toleransi (tidak se-ideal pada simulasi), nilai komponen aktif yang tidak seideal datasheet dan bersifat ESD (Electro Static Discharge), pengikisan jalur mikrostrip yang terlalu dalam saat fabrikasi, pengaruh noise internal yang tinggi dan terdapat loss pada sambungan kabel antara signal generator dan, rangkaian rectifier, serta sambungan kabel pada port VNA ke rangkaian rectifier.

\section{REFERENSI}

1] Balanis, C.A. 2005, Antenna Theory Third Edition : Analysis and Design, USA : John Wiley \& Sons, INC.

[2] Bahan Ajar Materi Penyesuaian Impedansi. Politeknik Negeri Bandung.

[3] D. Pavone, A. Buonanno, M. D. Urso, and F. D. Corte,'Design Considerations For Radio Frequency Energy Harvesting Devices", Progress In Electromagnetics Research B, vol. 45, pp. 19-35, 2012.

[4] Fakultas Teknik (2015), Buku Panduan Penyusunan Skripsi dan Non Skripsi, Jakarta, UNJ

[5] Herdiana, Budi, dkk, 2014, Rangkaian Penyearah RF ke DC Bertingkat untuk Multi Frekuensi Kerja pada Sistem Pengisian Listrik Secara Nirkabel, Bandung : LIPI 40-44.

[6] Jabbar, Hamid, 2010, RF Energy Harvesting System And Circuits For Charging Of Mobile Devices, IEEE

[7] Oka, Azlul Fadhly 2011, Skirpsi : Rancang Bangun Prototipe Sistem Daya Telepon Selular Berbasis RF Enerrgi Harvesting Dan Sel Surya, Progra studi teknik elektro fakultas teknik, Universitas Indonesia.

[8] Stefan Tudose, Dan, 2013, Rectifier Antenna Design for Wireless Sensor Networks, IEEE

[9] Sugiyono, 2009. Metode Penelitian kuantitatif, kualitattif dan $R \& D$, Bandung: Penerbit Alfabeta.

[10] Malvino, terj. Hanapi Gunawan., 1979, Prinsip-Prinsip Elektronik, 2nd Ed., Jakarta: Erlangga.

[11] Paradiso, J, A dan Starner, T, 2005, Energy Scavenging For Mobile And Wireless Electronics, IEEE Pervasive Computing, 4, pp. 18-27

[12] Zhang J. Dan Huang Y, 2007, Rectennas For Wireless Energy Harvesting, Departement Of Electrical Engineering And Electronics, University of Liverpool, pp 22

[13] William C Brown, 1974, The Tecnology And Application Off Free Space Power Transmission By Microwave Beam, proceddings of the IEEE, vol. 62, pp 11-25.

[14] Michelon, Dino, dkk, 2014, Optimization of Integrated Dickson Voultage Multiplier For RF Energy Harvesting, IEEE 